\title{
Possible Involvement of Mitochondrial Reactive Oxygen Species Production in Protein Degradation Induced by Heat Stress in Avian Muscle Cells
}

\author{
Kyohei Furukawa, Motoi Kikusato, Tomomi Kamizono, Hayami Yoshida and Masaaki Toyomizu \\ Animal Nutrition, Life Sciences, Graduate School of Agricultural Science, Tohoku University, \\ 1-1 Tsutsumidori-Amamiyamachi, Aoba-ku, Miyagi, Sendai 981-8555, Japan
}

\begin{abstract}
Heat stress (HS) stimulates mitochondrial reactive oxygen species (ROS) production and protein degradation in skeletal muscle. The present study investigated the stimulatory effects of HS-induced mitochondrial ROS production on the ubiquitin-proteasome protein degradation system in primary cultured avian muscle cells. Cells were isolated from the breast muscle of neonatal chicks, and then grown for $48 \mathrm{~h}$. Thereafter, the cells were subjected to $37^{\circ} \mathrm{C}$ or $41^{\circ} \mathrm{C}$ (HS). Exposure to $6 \mathrm{~h}$ of HS treatment significantly decreased the cellular protein content compared to that of normal cells, an effect was completely suppressed by the addition of a proteasome-specific inhibitor. Whereas the mRNA levels of the $20 \mathrm{~S}$ proteasome $\mathrm{C} 2$ subunit, which is one of the subunits of the $26 \mathrm{~S}$ proteasome, did not change at any time during HS treatment $(1,3,6 \mathrm{~h})$, the mRNA levels of atrogin-1 and muscle ring-finger protein 1 , both of which are muscle-specific ubiquitin ligases, increased after $1 \mathrm{~h}$ of HS but then decreased to near-normal values with time. Intracellular ROS production (the sum of $\mathrm{H}_{2} \mathrm{O}_{2}$, hydroxyl radicals, peroxyl radicals, peroxynitrite) did not change in the $1 \mathrm{~h}$ HS-exposed cells, but was significantly increased after $3 \mathrm{~h}$ and $6 \mathrm{~h}$ of HS. Mitochondrial superoxide production was significantly increased after $1 \mathrm{~h}$ of HS, which might increase the mRNA expression of ubiquitin ligase in muscle cells. In cells pretreated with 4-hydroxy TEMPO, which is able to decrease mitochondrial superoxide production, the increases in mitochondrial superoxide production and ubiquitin ligase mRNA levels observed after $1 \mathrm{~h}$ of HS were suppressed. The protein content of these cells was not decreased, which was observed after the longest period of HS $(6 \mathrm{~h})$. These findings suggest that mitochondrial superoxide production may play an important role in activating the ubiquitin-proteasome system, probably via the induction of ubiquitin ligases, in HS-exposed muscle cells.
\end{abstract}

Key words: atrogin-1, 4-Hydroxy Tempo, mitochondria superoxide, MuRF1, skeletal muscle cells, ubiquitinproteasome system

J. Poult. Sci., 52: 260-267, 2015

\section{Introduction}

As birds lack sweat glands and are covered with feathers, heat dissipation from their body surface is restricted. Therefore, birds face the threat of hyperthermia. Several physiological and pathological stimuli such as exposure to high temperature (referred to as heat stress, HS), excessive inflammation and sepsis are known to cause hyperthermia in animals. In birds reared under HS conditions, plasma corticosterone levels are increased (Yunianto et al., 1997; Willemsen et al., 2011), which may contribute to the rapid turnover of muscle protein (Yunianto et al., 1997). Several

Received: February 9, 2015, Accepted: April 5, 2015

Released Online Advance Publication: May 25, 2015

Correspondence: M. Kikusato Ph.D., Animal Nutrition, Life Sciences,

Graduate School of Agricultural Science, Tohoku University, 1-1

Tsutsumidori-Amamiyamachi, Aoba-ku, Miyagi, Sendai 981-8555, Japan.

(E-mail: kmotoi@bios.tohoku.ac.jp) studies have also reported that HS treatment of cultured muscle cells results in an enhancement of protein degradation (Baracos et al., 1984; Luo et al., 2000; Nakashima et al., 2004a), which allows us to postulate that an intracellular intermediator could play a role in driving protein degradation in HS-exposed cells.

Overproduction of reactive oxygen species (ROS) is one of the hallmarks of HS (Zuo et al., 2000; Wang et al., 2013), and our previous studies have shown that this overproduction mainly occurs in the mitochondria (Mujahid et al., 2005; Kikusato and Toyomizu, 2013a). Recent research has proposed that mitochondrial ROS play an important role in intracellular signal transduction (Finkel, 2012), through which they also seem to contribute to protein catabolism (Li et al., 2003a; Gilliam et al., 2012; Rahman et al., 2014). The ubiquitin-proteasome system is a major proteolytic pathway within cells, and comprises two different processes, protein ubiquitination and proteasomal degradation. In these 
processes, proteins undergo ubiquitination via a series of reactions involving ubiquitin-activating enzyme (E1), ubiquitin-conjugating enzyme (E2) and ubiquitin ligase (E3), before being subsequently decomposed by the $26 \mathrm{~S}$ proteasome. It has been reported that HS activates this system, thereby contributing to protein degradation in skeletal muscle cells (Morita et al., 1996; Luo et al., 2000; Nakashima et al., 2004). Based on these lines of evidence, it can be hypothesized that mitochondrial ROS production may be a factor that activates the ubiquitin-proteasome system under HS conditions. In support of this idea, our previous study found that antioxidant treatment reverses the decrease in cellular protein content that occurs due to HS treatment (Yoshida et al., 2013).

To assess the stimulatory effect of mitochondrial ROS on protein degradation in HS-exposed cells, we examined concomitant changes in cellular protein content, the mRNA levels of ubiquitin-proteasome-related genes and mitochondrial ROS production levels in response to different periods of HS treatment, using primary cultured avian skeletal muscle cells. We also measured the changes in cellular protein levels in response to an antioxidant which is able to reduce mitochondrial superoxide, the major radical species generated in this organelle. Here, we demonstrate that mitochondrial superoxide production may play an important role in activating the ubiquitin-proteasome protein degradation system, thereby decreasing the protein content of HS-exposed muscle cells.

\section{Materials and Methods}

\section{Ethics Statement}

The Animal Care and Use Committee of the Graduate School of Agricultural Science, Tohoku University, approved all procedures, and every effort was made to minimize pain or discomfort to the animals.

\section{Cell Culture}

Skeletal muscle cells were isolated from the superficial pectoralis muscles of male neonatal chicks. Five 0-day-old male chicks (Ross strain, Gallus gallus domesticus) were obtained from a commercial hatchery (Matsumoto Poultry Farms and Hatcheries Co., Ltd., Zao, Miyagi, Japan). The muscles were dissected and digested with a mixture of collagenase $(1 \mathrm{mg} / \mathrm{ml})$ and dispase $(1000 \mathrm{U} / \mathrm{m} l)$ for $20 \mathrm{~min}$ at $37^{\circ} \mathrm{C}$. Cells were collected by centrifugation, washed and resuspended in basal medium (80\% Dulbecco's Modified Eagle's Medium (DMEM), 20\% M199) supplemented with $10 \%$ fetal bovine serum (FBS), $1.5 \times 10^{5} \mathrm{U} / l$ penicillin and $0.15 \mathrm{~g} / \mathrm{l}$ streptomycin. The cell suspension was transferred to $\phi 90 \mathrm{~mm}$-dishes to allow fibroblast attachment, and unattached cells were then collected. The cells were seeded onto collagen Type I-coated $\phi 60 \mathrm{~mm}$-dishes or 24 -well microplates at a density of $4.5 \times 10^{4}$ cells $/ \mathrm{cm}^{2}$ for each measurement, and were incubated for $48 \mathrm{~h}$ at $37^{\circ} \mathrm{C}$ under $95 \%$ air $/ 5 \%$ $\mathrm{CO}_{2}$ until the cells reached sub-confluence. For the subsequent experiments, the cells were incubated in the medium without FBS and exposed to normal $\left(37^{\circ} \mathrm{C}\right)$ or $\mathrm{HS}\left(41^{\circ} \mathrm{C}\right)$ conditions for a given time $(1,3$ or $6 \mathrm{~h})$. Although rectal temperature of chicken is around $41^{\circ} \mathrm{C}$, the present study adopted general incubation temperature $\left(37^{\circ} \mathrm{C}\right)$ as usually used for elucidating avian muscle metabolisms (Nakashima et al., 2004a, 2004b; Joubert et al., 2011; Sato et al., 2012). Measurement of Intracellular ROS Production and Mitochondrial Superoxide Production

Intracellular ROS production in muscle cells was fluorometrically determined using 5-(and-6) -chloromethyl-2'7'dichlorodihydrofluorescein diacetate, acetyl ester $\left(\mathrm{CM}-\mathrm{H}_{2}\right.$ DCFDA, Life Technologies, San Diego, CA, USA) as previously described (Yoshida et al., 2013). CM- $\mathrm{H}_{2}$ DCFDA undergoes deacetylation by cytosolic esterases to form dichlorodihydrofluorescein. This then reacts with ROS, such as hydrogen peroxide, hydroxyl radicals, peroxyl radicals and peroxynitrite, to give rise to fluorescein. Mitochondrial superoxide production was detected using MitoSOX ${ }^{\mathrm{TM}}$ Red Mitochondrial Superoxide Indicator (Life Technologies, San Diego, CA, USA), which is a fluorescent dye for the highly selective detection of mitochondrial superoxide within cells. After HS treatment, the medium was replaced with $37^{\circ} \mathrm{C}$ - or $41^{\circ} \mathrm{C}$-prewarmed Hanks' balanced salt solution (HBSS) supplemented with either $5 \mu \mathrm{M} C \mathrm{CM}-\mathrm{H}_{2}$ DCFDA or $5 \mu \mathrm{M}$ MitoSOX ${ }^{\mathrm{TM}}$ Red, and each generation rate was measured as the change in fluorescence at excitation and emission wavelengths $(\lambda \mathrm{ex} / \lambda \mathrm{em})$ of $485 \mathrm{~nm} / 538 \mathrm{~nm}$ for $\mathrm{CM}-\mathrm{H}_{2}$ DCFDA and $510 \mathrm{~nm} / 590 \mathrm{~nm}$ for MitoSOX ${ }^{\mathrm{TM}}$ Red, for $30 \mathrm{~min}$ each. The assay was carried out on a computer-controlled fluorescence microplate reader (Ascent Fluoroskan, Thermo Scientific, Waltham, MA, USA) at $37^{\circ} \mathrm{C}$ or $41^{\circ} \mathrm{C}$. Both dyes were dissolved in dimethyl sulfoxide (DMSO), and this was then added to HBSS to make a $0.1 \%$ solution. The fluorescence intensity was normalized against the protein value.

An antioxidant, 4-hydoxy TEMPO (Tmp) (5 mM), which is able to permeate the mitochondrial membrane, mimic superoxide dismutase (Krishna et al., 1996) and act as a superoxide scavenger (Laight et al., 1997), was added to the incubation medium with FBS for $1 \mathrm{~h}$ prior to HS treatment to examine the involvement of superoxide in the ubiquitinproteasome system under HS conditions.

\section{Measurement of Cellular Protein Content}

The cells were washed twice with phosphate buffered saline (PBS), collected with $2 \%$ sodium dodecyl sulfate, and stored at $-20^{\circ} \mathrm{C}$ until required. The protein content was determined using the micro bicinchoninic acid (microBCA) assay (Thermo Scientific, Waltham, MA, USA), with bovine serum albumin as the standard. The absorbance at $550 \mathrm{~nm}$ wave length was detected using an iMark $^{\mathrm{TM}}$ Microplate Reader (Bio-Rad, Hercules, CA, USA).

Proteasome Inhibitor I $(20 \mu \mathrm{M})$ (Merck Millipore, Billerica, MA, USA) was used to inhibit the chymotrypsin-like activity of the 20S proteasome (Figueiredo-Pereira et al., 1994), which is a multicatalytic proteinase unit of the $26 \mathrm{~S}$ proteasome. The inhibitor was added to the incubation medium without FBS to examine its effect on cellular protein content. The inhibitor was dissolved in DMSO, and this was then added to the above medium to make a $0.1 \%$ solution prior to HS treatment. 
Quantification of mRNA Expression using Real-time Polymerase Chain Reaction (RT-PCR)

The effects of HS treatment on the mRNA levels of genes related to the ubiquitin-proteasome system, such as atrogin1, muscle ring-finger protein-1 (MuRF1) and the 20S proteasome $\mathrm{C} 2$ subunit, were determined by real-time RTPCR analysis using a CFX Connect ${ }^{\mathrm{TM}}$ system (Bio-Rad Laboratories, Hercules, CA, USA). Isolation of tissue RNA and synthesis of cDNA were conducted as previously described (Yoshida et al., 2013), with minor modifications. The results are presented as ratios of the target mRNA to $18 \mathrm{~S}$ ribosomal RNA (18S) levels, to correct for differences in the amounts of template cDNA used. The primer sequences used to amplify the target genes were as follows: atrogin-1 (sense 5' -CCA ACA ACC CAG AGA CCT GT-3', antisense 5'-GGA GCT TCA CAC GAA CAT GA-3' (Nakashima et al., 2006): NM_001030956.1), MuRF1 (sense 5'-TGT CTA CGG GCT GCA GAG GAA-3', antisense 5'-GGT GCT CCC CCT TCT TGA GT-3': XM_424369.2), the 20S proteasome $\mathrm{C} 2$ subunit (sense $5^{\prime}$-AAC ACA CGC TGT TCT GGT TG-3', antisense 5' - CTG CGT TGG TAT CTG GGT TT-3' (Nakashima et al., 2009): AF027978) and 18S (sense 5'-TAG ATA ACC TCG AGC CGA TCG-3', antisense 5' GAC TTG CCC TCC AAT GGA TCC-3' (Abe et al., 2006): AF173612.1).

\section{Statistical Analysis}

All data are expressed as the mean \pm standard error (SE) of 4-9 individual samples. Statistical differences between the groups were identified using the Student's $t$-test or one-way analysis of variance (ANOVA), followed by the TukeyKramer multiple comparisons test. $P<0.05$ was considered statistically significant.

\section{Results}

Effect of HS on Cellular Protein Levels and the Effect of the Proteasome Inhibitor in Avian Muscle Cells

To evaluate the involvement of the ubiquitin-proteasome protein degradation system in the decrease in protein levels

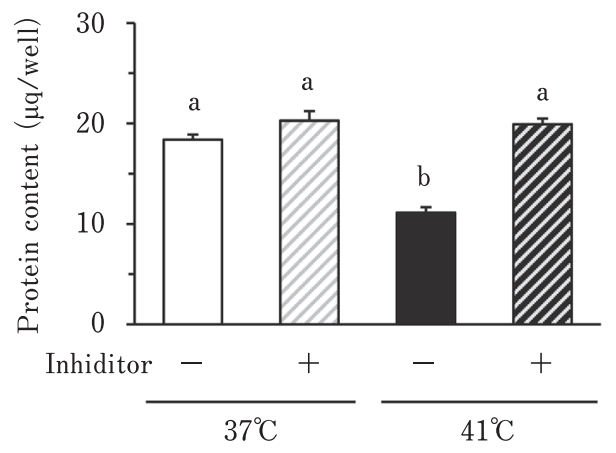

Fig. 1. Effects of a 20S proteasome-specific inhibitor on the cellular protein content in $6 \mathrm{~h}$ hypothermia-exposed avian muscle cells. The protein content was measured using the microBCA method. Values are means $\pm \mathrm{SE}, n$ $=9$. ${ }^{\mathrm{a}, \mathrm{b}} P<0.05$, for each treatment; values with different letters are statistically different. due to HS treatment, cells were co-incubated with a specific inhibitor of the $20 \mathrm{~S}$ proteasome during HS conditions. Whereas the protein content of the non-treated cells was significantly decreased by HS treatment compared to that of normal cells, this decrease was not observed in the proteasome inhibitor-treated cells (Fig. 1). In addition, the proteasome inhibitor had little effect on the protein content at normal temperatures. These results suggest that the ubiquitinproteasome system may play a critical role in the decrease in cellular protein content that occurs due to HS treatment.

Time Course of Changes in Protein Content and mRNA Levels of Ubiquitin-proteasome Protein Degradation Systemrelated Genes During HS Conditions

The time-dependent effects of HS treatment on the cellular protein and mRNA levels of ubiquitin-proteasome-related genes such as atrogin-1, MuRF1 and the proteasome C2 subunit were evaluated. As illustrated in Fig. 2A, there was no change in the protein content after $1 \mathrm{~h}$ of HS treatment, whereas a decrease was recorded after longer periods $(3 \mathrm{~h}, 6$ h). Little difference in the degree of the reduction in protein content was observed between the $3 \mathrm{~h}$ and $6 \mathrm{~h}$ HSexposed cells. These results suggest that the decrease in protein content that occurred due to the $3 \mathrm{~h}$ HS treatment might be carried over into the protein levels observed at the $6 \mathrm{~h}$ time point. Atrogin-1 and MuRF1 are muscle-specific ubiquitin ligases (Bodine and Baehr, 2014). The mRNA levels of these atrogenes seem to be susceptible to proteolytic conditions such as fasting (Nakashima et al., 2006; Ohtsuka et al., 2011). As seen in Fig. 2, the mRNA levels of atrogin1 (B) and MuRF1 (C) were significantly increased after $1 \mathrm{~h}$ of HS treatment, but subsequently diminished with longer periods of HS conditions. After $6 \mathrm{~h}$ of HS treatment, the atrogin-1 mRNA level was significantly lower than that in normal cells, and the MuRF1 mRNA level was restored to near-normal values. In addition, the mRNA level of the proteasome $\mathrm{C} 2$ subunit, which is one of the major subunits of the $20 \mathrm{~S}$ proteasome that is a multicatalytic component of the $26 \mathrm{~S}$ proteasome, did not vary at any stage of HS treatment (Fig. 2D). Overall the results suggest that protein ubiquitination may be augmented at the earlier stage of HS treatment, and that these proteins might subsequently undergo proteasomal degradation.

Changes in Intracellular ROS Production and Mitochondrial Superoxide Production During HS Conditions

The time course of changes in intercellular ROS production and mitochondrial superoxide production during HS conditions were evaluated to investigate if they changed in parallel with the changes in ubiquitin ligase mRNA levels. As illustrated in Fig. 3A, intracellular ROS production was not affected by the $1 \mathrm{~h}$ HS treatment, but was significantly increased by the $3 \mathrm{~h}$ and $6 \mathrm{~h}$ treatments compared to normal cells. In contrast, mitochondrial superoxide production was significantly increased by the $1 \mathrm{~h}$ HS treatment, with an increase still being observed at the $6 \mathrm{~h}$ time point (Fig. 3B). Scavenging Mitochondrial Superoxide Reduces Atrogenes mRNA Levels in HS-exposed Cells

Given our finding of simultaneous increases in mitochon- 


\section{A}

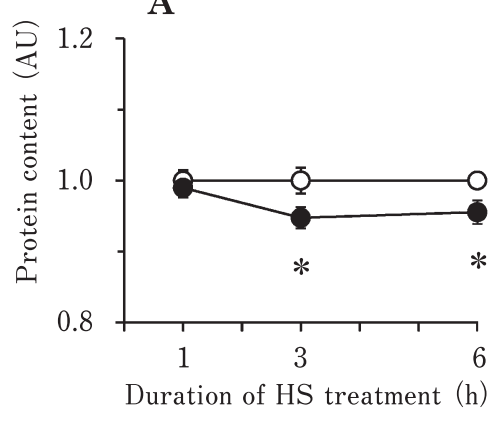

B

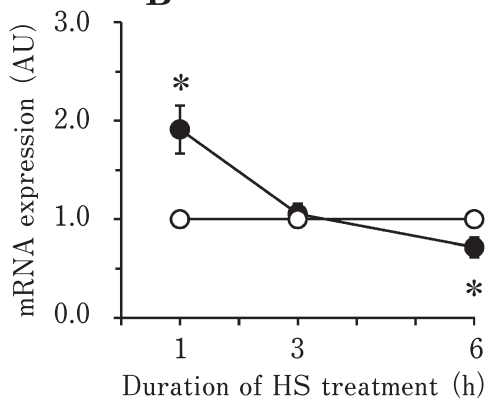

C

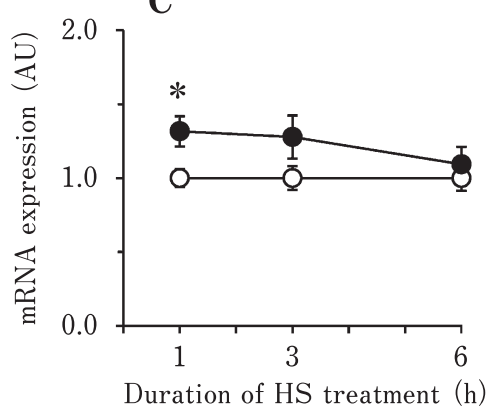

D

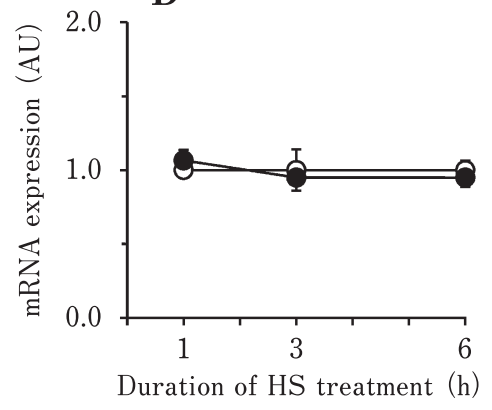

Fig. 2. Time-dependent effects of on cellular protein content (A), and the mRNA levels of atrogin-1 (B), MuRF1 (C) and the 20S proteasome $\mathrm{C} 2$ subunit (D) in avian muscle cells. Real-time RT-PCR was used to quantify the mRNA levels, and the results were normalized to $18 \mathrm{~S}$ transcript levels. The values were expressed as fold change relative to the control values at each time point. Values are means $\pm \mathrm{SE}, n=$ $4-8$. $* P<0.05$ compared to the control values at each time point.

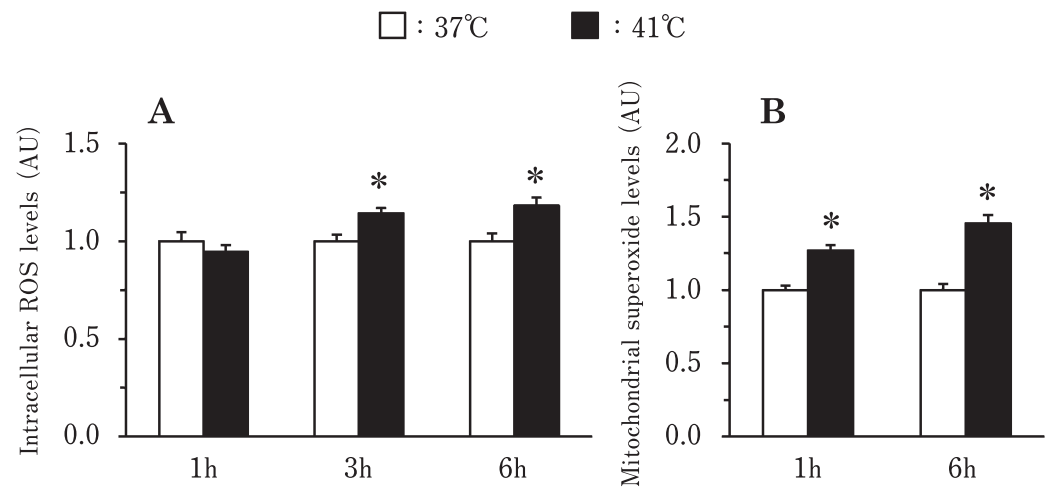

Fig. 3. Time-dependent effects of HS on intracellular ROS production (A) and mitochondrial superoxide production (B) in avian muscle cells. Intracellular ROS production and mitochondrial superoxide production were fluorometrically determined using $\mathrm{CM}-\mathrm{H}_{2}$ DCFDA and MitoSOX ${ }^{\mathrm{TM}}$ Red, respectively, with the results being corrected for protein levels. Values are means \pm SE, $n=7-8$. $* P<0.05$ compared to the control values at each time point.

drial superoxide production (Fig. 3B) and the atrogenes (atrogin-1 and MuRF1) mRNA levels in the $1 \mathrm{~h}$ HS-exposed cells (Fig. 2B-2C), we hypothesized that mitochondrial superoxide production could play an influential role in inducing the transcription of these genes in HS-exposed cells. To verify this, Tmp was added to muscle cells prior to HS 
A

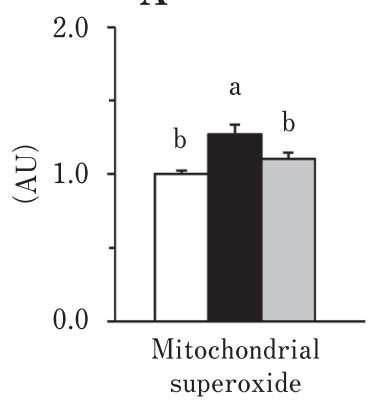

B

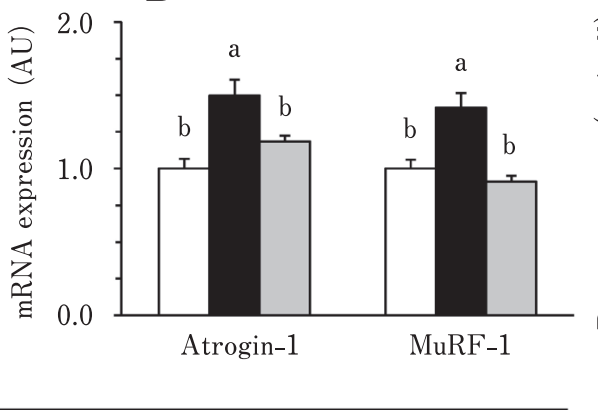

$1 \mathrm{~h}$

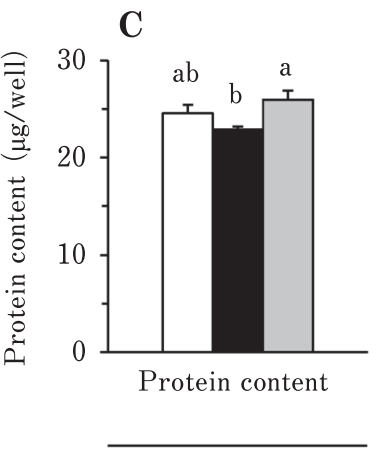

$6 \mathrm{~h}$

Fig. 4. Suppressive effects of Tmp on mitochondrial superoxide production (A), mRNA levels of ubiquitin ligases (B) and cellular protein content $(C)$ in $1 \mathrm{~h}$ or $6 \mathrm{~h}$ HS-exposed avian muscle cells. Mitochondrial superoxide radical levels were fluorometrically determined using MitoSOX ${ }^{\mathrm{TM}}$ Red, with the results being corrected for protein levels. Real-time RT-PCR was used to quantify the mRNA levels, and the results were normalized to $18 \mathrm{~S}$ transcript levels. Values are means $\pm \mathrm{SE}, n=5-6$. ${ }^{\mathrm{a}, \mathrm{b}} P<0.05$, for each treatment; values with different letters are statistically different.

treatment. As a result, mitochondrial superoxide production in Tmp-pretreated cells following $1 \mathrm{~h}$ of HS treatment was restored to near-normal values (Fig. 4A), and the atrogin-1 and MuRF1 mRNA levels in these cells were also significantly decreased (Fig. 4B). Moreover, following the longer HS treatment of these cells $(6 \mathrm{~h})$, the protein content was also restored to near-normal values (Fig. 4C). Overall these results suggest that mitochondrial superoxide production may play an important role in initiating protein ubiquitination via atrogin-1 and MuRF1 transcription at an early stage of HS treatment, and that proteasomal degradation might subsequently occur.

\section{Discussion}

In agreement with previous studies (Luo et al., 2000; Nakashima et al., 2004a), the present study has shown that HS stimulates the ubiquitin-proteasome system, which leads to protein degradation in skeletal muscle cells. It has also provided the first evidence that mitochondrial superoxide production may play an important role in evoking protein ubiquitination, thereby promoting proteasomal degradation in these cells. Several studies has reported that ROS (in many case, $\mathrm{H}_{2} \mathrm{O}_{2}$ ) may be associated with muscle protein catabolism via ubiquitin-conjugating activity and calpain-1 (Li et al., 2003b; McClung et al., 2009), and growing evidence suggests that mitochondria-derived ROS promote muscle atrophy and autophagy in skeletal muscle (Gilliam et al., 2012; Rahman et al., 2014). Thus, HS-induced mitochondrial superoxide production is also likely to play a pivotal role in initiating protein degradation.

The signal transduction mechanisms by which mitochon- drial superoxide production regulates transcription of atrogin-1 and MuRF1 genes should be considered. These atrogenes transcription are regulated by transduction pathways via nuclear factor-kappa $\mathrm{B}(\mathrm{NF}-\kappa \mathrm{B})$ or forkhead box $\mathrm{O}$ (FoxO) transcription factors (Bonetto et al., 2009). Li et al. (2003b) have reported that $\mathrm{H}_{2} \mathrm{O}_{2}$ is a weak activator of NF$\kappa \mathrm{B}$ in $\mathrm{C} 2 \mathrm{C} 12$ myotubes. FoxO activation (dephosphorylation) induces muscle atrophy via increases in the expression of these atrogenes (Sandri et al., 2004). Furthermore, protein kinase $\mathrm{B}(\mathrm{PkB}$, also known as $\mathrm{Akt})$ is one of the inhibitory factors that regulates FoxO via phosphorylation (Brunet et al., 1999), and it has been reported that acute nutrition deprivation stimulates mitochondrial superoxide production, which inhibits Akt, thereby dephosphorylating (activating) FoxO3a (Rahman et al., 2014). Based on these lines of evidence, one or some of the above factors might implicate in the induction of atrogin-1 and MuRF1 transcription under HS conditions. However, there is no information regarding on changes in the above factors in response to HS treatment as far as we know. When this is established, we will be in a position to better understand the mechanism that initiates the ubiquitination process under HS conditions.

Given that superoxide is not able to permeate the mitochondrial membrane, one issue that needs to be considered is at which mitochondrial sites superoxide is generated, thereby leading to ubiquitin ligase gene transcription in HS-exposed cells. Our previous studies using isolated mitochondria from HS-exposed birds showed that the overproduction of superoxide mainly occurred at complex I due to reverse electron flow (Kikusato and Toyomizu, 2013a). In this context, it is 
well known that complex I-dependent superoxide is released into the mitochondrial matrix (St-Pierre et al., 2002; Miwa et al., 2003), which allows us to assume that superoxide generated from different sources might be involved in the induction of atrogin-1 and MuRF1 transcription in HSexposed cells. Mitochondrial glycerol 3-phosphate dehydrogenase (mGPDH) is one of the major sources of superoxide production in mitochondria (Drahota et al., 2002; Miwa et al., 2003; Tretter et al., 2007), and ROS generated by this enzyme are equally released to both sides of the mitochondrial inner membrane (Miwa and Brand, 2005; Orr et al., 2012). In this regard, we have recently obtained evidence that HS stimulates superoxide production via mGPDH in isolated muscle mitochondria (Kikusato and Toyomizu, $2013 b)$. It is therefore conceivable that superoxide generated from mGPDH might induce the transcription of ubiquitin ligase genes, thereby activating the ubiquitination process under HS conditions.

Whereas mitochondrial superoxide production may play an influential role in inducing transcription of the atrogenes in $1 \mathrm{~h}$ HS-exposed cells, these up-regulation did not occur in $6 \mathrm{~h}$ HS-exposed cells in spite of the increase in the mitochondrial superoxide levels (Fig. 2B, 2C and Fig. 3B). It can be assumed that an increase in $\mathrm{Cu} / \mathrm{Zn}$-superoxide dismutase (SOD1) or cytochrome $c$ might be involved in the discrepancy observed in these cells. They are unable to eliminate superoxide radical released into the mitochondrial matrix, but are able to the radical released into the intermembrane space (Pereverzev et al., 2003; Iñarrea et al., 2005). From these findings, it was suggested that SOD1 or cytochrome $c$ expression might be increased in $6 \mathrm{~h}$ HSexposed cells, thereby abolishing the effect of mitochondrial superoxide on the atrogenes transcription. However, our previous study showed that the mRNA levels of SOD1 were not changed in $6 \mathrm{~h}$ HS-exposed cells (Yoshida et al., 2013). Thus, we infer that an increase in cytochrome $c$ activity might disable the effect of mitochondrial superoxide in such conditions.

The ubiquitin-proteasome protein degradation system comprises ubiquitination and proteasomal degradation processes. The present study showed that the treatment of HSexposed cells with a proteasome inhibitor resulted in a suppression of the decrease in protein content (Fig. 1). From this experimental fact, we considered that proteasomal degradation process would also be induced by exposure to HS. However, the present study showed that proteasome C2 subunit mRNA levels were not altered in HS-exposed cells (Fig. 2D). Therefore, it has to be considered whether proteasomal degradation was increased in response to HS and how cellular protein was decomposed by the ubiquitinproteasome system in HS-exposed cells. We proposed two possible explanations to these questions. Firstly, proteasomal degradation in HS-exposed cells may not be changed in accordance with proteasome C2 subunit mRNA levels (Fig. 2D), and therefore only an ubiquitination may be the ratelimiting reaction for inducing protein degradation in these cells. Recent researches have suggested that the transcrip- tion of proteasome seems to also be induced when the proteolysis activity is increased (Kobayashi et al., 2004; Itoh et al., 2004; Taguchi et al., 2011). Several proteasome subunits is induced through nuclear factor E2-related factor 2 (Nrf2)-Kelch-like ECH-associated protein 1 (Keap1) pathway. In this pathway, Nrf2 is constantly degraded via the ubiquitin-proteasome pathway in a Keap1-dependent manner under normal conditions, while this degradation ceases in the presence of electrophiles or ROS. Accumulated Nrf2 then activates target genes for cytoprotection including proteasome subunits. It can be therefore assumed that these transcriptional events might not occur in HS-exposed cells. Secondly, proteasomal proteolysis may be induced independent of the above transcription pathway. This idea is supported by the report of Morita et al. (1996). They showed that hyperthermic treatment of $\mathrm{C} 2 \mathrm{C} 12$ myotubes resulted in an increase in the $26 \mathrm{~S}$ proteasome activity but not in the mRNA levels. In view of this finding, it is possible that proteasomal proteolysis may also be increased without an increase in the transcription in response to HS, though the precise machinery inducing proteasomal activity remains unclear. Thus, in order to determine whether proteasomal degradation is enhanced due to HS treatment, Nrf2/Keap1 pathway and/or proteasomal activity are required to be investigated.

In order to give a new insight into HS-induced protein catabolism in vivo, it is also important to consider an endocrine factor affecting transcription of atrogin-1 and MuRF1 genes, because it is a major difference between in vivo and in vitro experiments. Plasma corticosterone levels were increased in response to HS treatment (Yunianto et al., 1997; Willemsen et al., 2011), and this glucocorticoide seems to increase mRNA levels of the atrogenes in cultured myotubes (Menconi et al., 2008). Moreover, it has been reported that circulating levels of tumor necrosis factor- $\alpha$ (TNF- $\alpha)$ and its muscular mRNA levels were also increased in response to HS treatment (Welc et al., 2012). TNF- $\alpha$ is known to stimulate mitochondrial superoxide production ( $\mathrm{Li}$ et al., 1999; Corda et al., 2001; Kastl et al., 2014), and is able to activate NF- $\kappa$ B signal transduction, which is one of pathways responsible for inducing the atrogenes transcription as above mentioned. From these lines of findings, it is highly likely that there is more complicated mechanisms that induces protein catabolism in birds reared under HS conditions. For future research, it is important to elucidate the role of mitochondrial superoxide production in the intracellular and extracellular mechanisms occurred in heat stressed-birds.

In the present study, avian muscle cells were subjected to $41{ }^{\circ} \mathrm{C}$ conditions, which is approximately same as body temperature of domestic chickens. Therefore, it can be suggested that hyperthermic treatment with higher than $41^{\circ} \mathrm{C}$ should be conducted to investigate avian species-specific protein catabolism. Our previous study reported that little difference in decreases in protein levels was observed between $41^{\circ} \mathrm{C}$ and $43^{\circ} \mathrm{C}$ HS-exposed in the presence of FBS (Yoshida et al., 2013), which allowed us to assume that protein catabolism might be temperature-independent in 
avian muscle cells. However, we consider that more detailed investigation is required in order to determine the avian protein catabolism in response to hyperthermic conditions.

In conclusion, the present study provides insight into the mechanism that regulates the intracellular protein degradation system in HS-exposed muscle cells: overproduction of mitochondrial superoxide may play an important role in initiating the ubiquitin-proteasome system.

\section{Acknowledgment}

This work was supported by a Grant-in-Aid for Scientific Research from the Ministry of Education, Science and Culture of Japan (24380147: M.T; 25850182: M.K). Acknowledgment is also made to the Japan Poultry Science Association for providing a travel grant to K.F. to allow presentation of some of the findings at the 10th Asian Pacific Poultry Conference, Jeju, Korea

\section{References}

Abe T, Mujahid A, Sato K, Akiba Y. and Toyomizu M. Possible role of avian uncoupling protein in down-regulating mitochondrial superoxide production in skeletal muscle of fasted chickens. FEBS Letters. 580: 4815-4822. 2006.

Baracos VE, Wilson EJ, and Goldberg AL. Effects of temperature on protein turnover in isolated rat skeletal muscle. American Journal of Physiology. 246: C125-C130. 1984.

Bodine SC and Baehr LM. Skeletal muscle atrophy and the E3 ubiquitin ligases MuRF1 and MAFbx/atrogin-1. American Journal of Physiology, Endocrinology and Metabolism. 307: E469-E484. 2014.

Bonetto A, Penna F, Muscaritoli M, Minero VG, Rossi Fanelli F, Baccino FM and Costelli P. Are antioxidants useful for treating skeletal muscle atrophy? Free Radical Biology and Medicine. 47: 906-916. 2009.

Brunet A, Bonni A, Zigmond MJ, Lin MZ, Juo P, Hu LS, Anderson MJ, Arden KC, Blenis J and Greenberg ME. Akt promotes cell survival by phosphorylating and inhibiting a Forkhead transcription factor. Cell. 96: 857-868. 1999.

Corda S, Laplace C, Vicaut E and Duranteau J. Rapid reactive oxygen species production by mitochondria in endothelial cells exposed to tumor necrosis factor- $\alpha$ is mediated by ceramide. Amerian Journal of Respiratory Cell and Molecular Biology. 24: 762-768. 2001.

Drahota Z, Chowdhury SK, Floryk D, Mrácek T, Wilhelm J, Rauchová H, Lenaz G and Houstek J. Glycerophosphatedependent hydrogen peroxide production by brown adipose tissue mitochondria and its activation by ferricyanide. Journal of Bioenergetics and Biomembranes. 34: 105-113. 2002.

Figueiredo-Pereira ME, Berg KA and Wilk S. A new inhibitor of the chymotrypsin-like activity of the multicatalytic proteinase complex (20S proteasome) induces accumulation of ubiquitinprotein conjugates in a neuronal cell. Journal of Neurochemistry. 63: 1578-1581. 1994.

Finkel T. Signal transduction by mitochondrial oxidants. Journal of Biological Chemistry. 287: 4434-4440. 2012.

Gilliam LA, Moylan JS, Patterson EW, Smith JD, Wilson AS, Rabbani $\mathrm{Z}$ and Reid MB. Doxorubicin acts via mitochondrial ROS to stimulate catabolism in $\mathrm{C} 2 \mathrm{C} 12$ myotubes. American Journal of Physiology, Cell Physiology. 302: C195-C202. 2012.
Itoh K, Tong KI and Yamamoto M. Molecular mechanism activating Nrf2-Keap1 pathway in regulation of adaptive response to electrophiles. Free Radical Biology and Medicine. 36: 1208-1213. 2004.

Iñarrea $\mathrm{P}$, Moini $\mathrm{H}$, Rettori $\mathrm{D}$, Han $\mathrm{D}$, Martínez $\mathrm{J}$, García I, Fernández-Vizarra E, Iturralde $\mathrm{M}$ and Cadenas E. Redox activation of mitochondrial intermembrane space $\mathrm{Cu}, \mathrm{Zn}$ superoxide dismutase. The Biochemical Journal. 387: 203209. 2005.

Joubert R, Métayer-Coustard S, Crochet S, Cailleau-Audouin E, Dupont J, Duclos MJ, Tesseraud S and Collin A. Regulation of the expression of the avian uncoupling protein 3 by isoproterenol and fatty acids in chick myoblasts: possible involvement of AMPK and PPAR $\alpha$ ? American Journal of Physiology Regulatroy, Integrative and Comparative Physiology. 301: R201-R208. 2011.

Kastl L, Sauer SW, Ruppert T, Beissbarth T, Becker MS, Süss D, Krammer PH and Gülow K. TNF- $\alpha$ mediates mitochondrial uncoupling and enhances ROS-dependent cell migration via NF- $\kappa$ B activation in liver cells. FEBS Letters. 588: 175-183. 2014.

Kikusato M and Toyomizu M. Crucial role of membrane potential in heat stress-induced overproduction of reactive oxygen species in avian skeletal muscle mitochondria. PLoS One. 8: e64412. 2013a.

Kikusato $\mathrm{M}$ and Toyomizu M. Heat stress-induced overproduction of mitochondrial ROS is down-regulated in laying-type chickens. Energy and protein metabolism and nutrition in sustainable production. EAAP publication. No. 134, p267-268. 2013b.

Kobayashi A, Kang MI, Okawa H, Ohtsuji M, Zenke Y, Chiba T, Igarashi $\mathrm{K}$ and Yamamoto $\mathrm{M}$. Oxidative stress sensor Keap1 functions as an adaptor for Cul3-based E3 ligase to regulate proteasomal degradation of Nrf2. Molecular and Cellular Biology. 24: 7130-7139. 2004.

Krishna MC, Russo A, Mitchell JB, Goldstein S, Dafni H and Samuni A. Do nitroxide antioxidants act as scavengers of $\mathrm{O}_{\overline{2}}$ or as SOD mimics? Journal of Biological Chemistry. 271: 26026-26031. 1996.

Laight DW, Andrews TJ, Haj-Yehia AI, Carrier MJ and Anggård EE. Microassay of superoxide anion scavenging activity in vitro. Environmental Toxicology and Pharmacology. 3: 65-68. 1997.

Li N, Ragheb K, Lawler G, Sturgis J, Rajwa B, Melendez JA and Robinson JP. Mitochondrial complex I inhibitor rotenone induces apoptosis through enhancing mitochondrial reactive oxygen species production. Journal of Biological Chemistry. 278: 8516-8525. 2003a.

Li YP, Atkins CM, Sweatt JD and Reid MB. Mitochondria mediate tumor necrosis factor- $\alpha / \mathrm{NF}-\kappa \mathrm{B}$ signaling in skeletal muscle myotubes. Antioxidants and Redox Signaling. 1: 97-104. 1999.

Li YP, Chen Y, Li AS and Reid MB. Hydrogen peroxide stimulates ubiquitin-conjugating activity and expression of genes for specific E2 and E3 proteins in skeletal muscle myotubes. American Journal of Physiology, Cell Physiology. 285: C806C812. 2003b.

Luo GJ, Sun X and Hasselgren PO. Hyperthermia stimulates energyproteasome-dependent protein degradation in cultured myotubes. American Journal of Physiology, Regulatory, Integrative and Comparative Physiology. 278: R749-R756. 2000.

McClung JM, Judge AR, Talbert EE and Powers SK. Calpain-1 is 
required for hydrogen peroxide-induced myotube atrophy. American Journal of Physiology, Cell Physiology. 296: C363C371. 2009.

Menconi M, Gonnella P, Petkova V, Lecker S and Hasselgren PO. Dexamethasone and corticosterone induce similar, but not identical, muscle wasting responses in cultured $\mathrm{L} 6$ and $\mathrm{C} 2 \mathrm{C} 12$ myotubes. Journal of Cellular Biochemistry. 105: 353-364. 2008.

Miwa S and Brand MD. The topology of superoxide production by complex III and glycerol 3-phosphate dehydrogenase in Drosophila mitochondria. Biochimica Biophysica Acta. 1709: 214-219. 2005.

Miwa S, St-Pierre J, Partridge L and Brand MD. Superoxide and hydrogen peroxide production by Drosophila mitochondria. Free Radical Biology and Medicine. 35: 938-948. 2003.

Morita S, Tsujinaka T, Yano M, Ebisui C, Morimoto T, Fujita J, Ogawa A, Taniguchi M, Shiozaki H and Monden M. Temperature-dependent enhancement of proteolysis in $\mathrm{C} 2 \mathrm{C} 12$ myotubes in association with the activation of $26 \mathrm{~S}$ proteasome. Biochemical and Biophysical Research Communications. 228: 813-818. 1996.

Mujahid A, Yoshiki Y, Akiba Y and Toyomizu M. Superoxide radical production in chicken skeletal muscle induced by acute heat stress. Poultry Science. 84: 307-314. 2005.

Nakashima K, Nonaka I, Yamazaki M and Abe H. Myofibrillar proteolysis in chick muscle cell cultures during heat stress. Animal Science Journal: 75: 353-360. 2004a.

Nakashima K, Nonaka I and Masaki S. Myofibrillar proteolysis in chick myotubes during oxidative stress. Journal of Nutritional Science and Vitaminology (Tokyo). 50: 45-49. $2004 \mathrm{~b}$.

Nakashima K, Yakabe Y, Yamazaki M and Abe H. Effects of fasting and refeeding on expression of atrogin-1 and $\mathrm{Akt} / \mathrm{FOXO}$ signaling pathway in skeletal muscle of chicks. Bioscience, Biotechnology and Biochemistry. 70: 2775-2778. 2006.

Nakashima K, Ishida A and Katsumata M. Comparison of proteolytic-related gene expression in the skeletal muscles of layer and broiler chickens. Bioscience, Biotechnology and Biochemistry. 73: 1869-1871. 2009.

Ohtsuka A, Kawatomi N, Nakashima K, Araki T and Hayashi K. Gene expression of muscle-specific ubiquitin ligase, atrogin1/MAFbx, positively correlates with skeletal muscle proteolysis in food-deprived broiler chickens. Journal of Poultry Science. 48: 92-96. 2011.

Orr AL, Quinlan CL, Perevoshchikova IV and Brand MD. A refined analysis of superoxide production by mitochondrial sn-glycerol 3-phosphate dehydrogenase. Journal of Biological Chemistry. 287: 42921-42935. 2012.

Pereverzev MO, Vygodina TV, Konstantinov AA and Skulachev VP. Cytochrome $c$, an ideal antioxidant. Biochemical Society Transactions. 31: 1312-1315. 2003.

Rahman M, Mofarrahi M, Kristof AS, Nkengfac B, Harel S and
Hussain SN. Reactive oxygen species regulation of autophagy in skeletal muscles. Antioxidant Redox Signaling. 20: 443459. 2014.

Sandri M, Sandri C, Gilbert A, Skurk C, Calabria E, Picard A, Walsh K, Schiaffino S, Lecker SH and Goldberg AL. Foxo transcription factors induce the atrophy-related ubiquitin ligase atrogin-1 and cause skeletal muscle atrophy. Cell. 117: 399412. 2004.

Sato K, Aoki M, Kondo R, Matsushita K, Akiba Y and Kamada T. Administration of insulin to newly hatched chicks improves growth performance via impairment of MyoD gene expression and enhancement of cell proliferation in chicken myoblasts. General and Comparative Endocrinology. 175: 457-463. 2012.

St-Pierre J, Buckingham JA, Roebuck S and Brand MD. Topology of superoxide production from different sites in the mitochondrial electron transport chain. Journal of Biological Chemistry. 277: 44784-44790. 2002.

Taguchi K, Motohashi H and Yamamoto M. Molecular mechanisms of the Keap1-Nrf2 pathway in stress response and cancer evolution. Genes to Cells. 16: 123-140. 2011.

Tretter L, Takacs K, Hegedus V and Adam-Vizi V. Characteristics of $\alpha$-glycerophosphate-evoked $\mathrm{H}_{2} \mathrm{O}_{2}$ generation in brain mitochondria. Journal of Neurochemistry. 100: 650-663. 2007.

Wang Z, Cai F, Chen X, Luo M, Hu L and Lu Y. The role of mitochondria-derived reactive oxygen species in hyperthermiainduced platelet apoptosis. PLoS One. 8: e75044. 2013.

Welc SS, Phillips NA, Oca-Cossio J, Wallet SM, Chen DL and Clanton TL. Hyperthermia increases interleukin-6 in mouse skeletal muscle. American Journal of Physiology, Cell Physiology. 303: C455-C466. 2012.

Willemsen H, Swennen Q, Everaert N, Geraert PA, Mercier Y, Stinckens A, Decuypere E and Buyse J. Effects of dietary supplementation of methionine and its hydroxy analog DL-2hydroxy-4-methylthiobutanoic acid on growth performance, plasma hormone levels, and the redox status of broiler chickens exposed to high temperatures. Poultry Science. 90: 23112320. 2011.

Yoshida H, Kikusato M, Souma K and Toyomizu M. The heatinduced production of reactive oxygen species regulates protein content in cultured chick skeletal muscle cells. Energy and protein metabolism and nutrition in sustainable production. EAAP publication. No. 134, p309-310. 2013.

Yunianto VD, Hayashi K, Kaneda S, Ohtsuka A and Tomita Y. Effect of environmental temperature on muscle protein turnover and heat production in tube-fed broiler chickens. British Journal of Nutrition. 77: 897-909. 1997.

Zuo L, Christofi FL, Wright VP, Liu CY, Merola AJ, Berliner LJ and Clanton TL. Intra- and extracellular measurement of reactive oxygen species produced during heat stress in diaphragm muscle. American Journal of Physiology, Cell Physiology. 279: C1058-C1066. 2000. 